\title{
miR-146a reduces depressive behavior by inhibiting microglial activation
}

\author{
CHUAN-PENG LIU ${ }^{1}$, MING ZHONG ${ }^{2}$, JUN-XIA SUN ${ }^{2}$, JIN HE $^{1}$, YONG GAO $^{1}$ and FANG-XIA QIN ${ }^{3}$ \\ ${ }^{1}$ Department of Psychiatry, Binzhou People's Hospital; ${ }^{2}$ Department of Psychiatry, \\ Binzhou Youfu Hospital, Binzhou, Shandong 256600; ${ }^{3}$ Department of Psychology, \\ Shandong Provincial Mental Health Center, Jinan, Shandong 250014, P.R. China
}

Received September 7, 2020; Accepted March 1, 2021

DOI: $10.3892 / \mathrm{mmr} .2021 .12102$

\begin{abstract}
Depression is one of the major psychiatric diseases affecting the quality of life for individuals worldwide. Numerous reports have investigated depression, although its etiology remains to be elucidated. microRNA (miR)-146a is suggested to regulate innate immune and inflammatory responses. However, it is unclear whether miR-146a is involved in depression. Depression model mice were established using lipopolysaccharide-induced depression and chronic unpredictable mild stress, separately. miR-146a mimic and short interfering RNA were used to treat depressed mice. Depression-like behaviors and levels of pro-inflammatory cytokines were measured, while ionized calcium binding adapter molecule 1 (Iba-1) expression in hippocampus was quantified by immunohistochemistry. Neuroinflammatory factor levels in hippocampus were measured by western blotting. BV-2 cells were used to confirm that miR-146a suppressed microglia activation. Compared with control mice, the two depressed mouse models showed clearly decreased sucrose preference and significantly increased immobility time in the forced swimming test and tail suspension test $(\mathrm{P}<0.05)$. miR-146a overexpression significantly increased sucrose preference and reduced immobility time in depressed mice $(\mathrm{P}<0.05)$. However, total distance traveled in the locomotor activity test did not differ among groups. Compared with controls, expression levels of Iba-1, inducible nitric oxide, IL-1 $\beta$, TNF- $\alpha$, interleukin 1 receptor associated kinase 1 (IRAK1), TNF receptor-associated factor 6 (TRAF6) and phosphorylated NF- $\mathrm{B}$ p 65 were significantly increased in depressed mice $(\mathrm{P}<0.05)$. miR-146a overexpression effectively inhibited expression of these neuroinflammatory proteins,
\end{abstract}

Correspondence to: Dr Fang-Xia Qin, Department of Psychology, Shandong Provincial Mental Health Center, 49 Wenhua East Road, Jinan, Shandong 250014, P.R. China

E-mail: qhacc9c@163.com

Key words: microRNA 146a, lipopolysaccharide, chronic unpredictable mild stress, microglia activation, neuroinflammatory factors while miR-146a silencing significantly upregulated their expression $(\mathrm{P}<0.05)$. Consistent with these in vivo results, miR-146a mimic treatment inhibited TNF- $\alpha$, IL-1 $\beta$, IRAK1 and TRAF6 expression in BV-2 cells. miR-146a improved depressive behaviors in depressed model mice by inhibiting microglial activation and neuroinflammatory factor expression.

\section{Introduction}

Depression is the fourth most prevalent disease in the world, with about 322 million individuals suffering from it worldwide, accounting for about $4.4 \%$ of the global population (1). Depression (and suicide) has begun to appear in those of increasingly younger age (in university students and even in primary and secondary school students). Common symptoms include inattention, negative self-evaluation, a sense of self-guilt and worthlessness (even in mild episodes), self-injuring or suicidal ideas or behaviors and sleep disorders (2). Depression does not belong to the class of neurodegenerative diseases, but its occurrence is closely related to microglial activation $(3,4)$.

Microglial activation occurs as a response to neuroinflammation and is a potential target for treating depression. Ionized calcium binding adapter molecule 1 (Iba-1) is a specific marker of microglial activation, which has been shown by previous studies to be significantly increased in the hippocampus of stressed rats (5). Activation of microglia can be classified into either M1 or M2 microglial activation (6). When M1 microglia are activated, expression levels of proinflammatory cytokines are raised, such as inducible nitric oxide synthase (iNOS), TNF- $\alpha$ and IL-1 $\beta$ (7). It is known that the abundant expression of Toll-like receptor (TLR) 4 induces microglial activation, triggering the association of recombinant interleukin 1 receptor-associated kinase 1 (IRAK1) and TNF receptor-associated factor 6 (TRAF6) (8). Thus, blocking microglial activation is of great importance in treating neuroinflammation-associated diseases, including depression.

miR-146 contains two evolutionarily conserved genes: miR-146a and miR-146b. In individuals, these loci are located at chromosomes 5 and 10 respectively and they differ by only 2 nucleotides at the 3 'terminus (9). In 2006, Taganov et al (10) first reported that miR-146a can suppress the immune response via the $\mathrm{NF}-\kappa \mathrm{B}$ signaling pathway. It also negatively 
regulates the expression of TLR4 pathway-related molecules and downstream inflammatory factors $(11,12)$. Studies have found that increasing miR-146a expression reduces microgliamediated neuroinflammatory responses, while silencing miR-146a expression induces the opposite effect $(13,14)$.

The present study investigated the effect of miR-146a on depression model mice and further investigated microgliamediated neuroinflammatory responses in hippocampal and BV-2 cells, including iNOS, TRAF6, IRAK1 and NF- $\kappa$ B.

\section{Materials and methods}

Animals. A total of 144 healthy male C57BL/6J mice, weighing 25-30 g at 6-8 weeks of age, were purchased from Jinan Pengyue Experimental Animal Breeding Co., Ltd. [animal production license no. SCXK (lu) 2014-0007]. All experiments followed the requirements for animal ethics specified by the Institutional Animal Care and Use Committee (IACUC) of Binzhou People's Hospital (approval no. 201910072). Mice were raised in a clean environment with a temperature of $20 \pm 2^{\circ} \mathrm{C}$, relative humidity of 50-70\%, 12-h light/dark cycle and food and water ad libitum. Following adaptive feeding for one week, animals underwent experimental grouping and model preparation.

Lipopolysaccharide (LPS)-induced depression model. Following Ren et al (15), animals were treated with LPS using intraperitoneal injection (ip) at $0.83 \mathrm{mg} / \mathrm{kg}$ for five consecutive days to establish the depression model.

Animal groups in LPS induced depression. In order to test the effect of miR-146a on LPS induced depression mice, 72 mice were divided into 6 groups, 12 mice in each group: i) Control group (Control; $0.9 \%$ saline, intraperitoneal injection); ii) LPS group (LPS; $0.83 \mathrm{mg} / \mathrm{kg}$, intraperitoneal injection); iii) miR-146a mimic (brain injection of miR-146a mimic and i.p. LPS); iv) mimic-negative control (NC; brain injection of miR-146a mimic NC and i.p. LPS); v) miR-146a short interfering (si)RNA (brain injection of miR-146a siRNA and i.p. LPS); and vi) siRNA-NC (brain injection of miR-146a siRNA NC and i.p. LPS). miR-146a mimic (5'-UGAGAACUG AAUUCCAUGGGUU-3'), miR-146a mimic negative control (5'-UUGUACUACACAAAAGUACUG-3'), miR-146a siRNA (5'-AACCCAUGGAAUUCAGUUCUCA-3') and miR-146a siRNA negative control (5'-CAGUACUUUUGUGUAGUA CAA-3') were all purchased from Guangzhou RiboBio Co., Ltd. One week before LPS injection, $1 \mu 1 \mathrm{miR}-146 \mathrm{a}$ $\operatorname{mimic}(0.5 \mathrm{nmol} / \mu \mathrm{l}), 5 \mu \mathrm{lmiR}-146 \mathrm{a} \operatorname{siRNA}(0.5 \mathrm{nmol} / \mu \mathrm{l})$ and $\mathrm{NC}(0.5 \mathrm{nmol} / \mu \mathrm{l})$ were injected into the hippocampus $(0.2 \mu \mathrm{l} / \mathrm{min})$ at $2.06 \mathrm{~mm}$ at antero-posterior, approximately $1.5 \mathrm{~mm}$ medio-lateral and $2 \mathrm{~mm}$ below the skull surface using a 33-gauge beveled NanoFil needle, a NanoFil syringe and a Microsyringe Pump Controller (16). The miR-146a mimic and siRNA were injected once every two days. After 1 week, animals were co-treated with LPS or normal saline using intraperitoneal injection for five consecutive days.

Chronic unpredictable mild stress (CUMS) depression model. Studies have shown that microglial cells are closely involved in the occurrence of depression $(3,17)$. Therefore, to further study the effect of miR-146a on depressed mice, a CUMS depression model was established. According to previous reports, the present study employed stimulation with different sources of stress, including fasting, water prohibition, isolation, cage tilting, cage emptying, diurnal inversion, restraint, environmental dampness, stroboscopic lighting and diurnal disturbance $(18,19)$. Every day, two or three stress sources were randomly selected and the model was repeated every Monday for five consecutive weeks.

Animal groups in CUMS depression. A total of 72 mice were divided into 6 groups, 12 mice in each group: i) Control group (Control), in which the mice were not treated; ii) depression group (CUMS), in which the CUMS model was induced in mice; iii) miR-146a-overexpressing control + depression group (mimic-NC+CUMS), in which one week before CUMS, mice were hippocampally injected with a blank vector containing miR-146a mimic; iv) miR-146a-overexpressing + depression group (miR-146a mimic+CUMS), in which one week before CUMS, mice were hippocampally injected with miR-146a mimic; v) miR-146a-silenced control + depression group (si-NC+CUMS), in which one week before CUMS, a blank vector containing miR-146a siRNA was hippocampally injected; and vi) miR-146asilenced + depression group (si-miR-146a+CUMS), in which one week before CUMS, the miR-146a siRNA was hippocampally injected.

\section{Behavioral testing}

Sucrose preference test (SPT). The test was divided into two parts, the training period and the testing period. During the 48-h training period, mice were given 2 bottles of sucrose water ( $1 \%$ concentration) during the first $24 \mathrm{~h}$ and 1 bottle of sucrose water ( $1 \%$ concentration) and 1 bottle of pure water during the second $24 \mathrm{~h}$. In the $8 \mathrm{~h}$ before the test, the mice did not eat, nor did they drink any water. During the test period of $2 \mathrm{~h}$, each animal was given 1 bottle of sucrose water $(1 \%$ concentration) and 1 bottle of pure water. To avoid biases in the results caused by positional preferences, the positions of the two bottles were changed after $1 \mathrm{~h}$ of testing. Following the test, the sucrose water preference index (sucrose water preference index $=$ sucrose water consumption/total liquid consumption $\mathrm{x} 100 \%$ ) was calculated (20).

Forced swimming test (FST). Mice were put in a transparent cylinder with a height of $\sim 22 \mathrm{~cm}$, a diameter of $\sim 14 \mathrm{~cm}$ and a water depth of $\sim 15 \mathrm{~cm}$. The water temperature was $\sim 20-25^{\circ} \mathrm{C}$. The forced swimming lasted for 6 min (21).

Tail suspension test (TST). The inverted tail of each mouse being tested was fixed to the tail suspension device, with the head of the mouse $\sim 5 \mathrm{~cm}$ away from the table, so that there was no place the mouse could grasp. There were baffles between the mice to block the line of sight, in order to prevent mutual interference. The percentage of time during the last 4 min that each mouse spent immobile within the complete 6 min testing time was recorded (22).

Locomotor activity. Locomotor activity was measured according to the protocol previously described (23). Briefly, 
each mouse was monitored in a $30 \times 30 \times 30 \mathrm{~cm}$ open-field cage. The total distance travelled by each mouse was measured over 30 min using open-field activity software (Med Associates). To avoid affecting the behavior of the next experimental animal, the cage was cleaned in between trials using $20 \%$ alcohol.

Reverse transcription-quantitative (RT-q) PCR. RT-qPCR was performed according to the manufacturer's instructions. Total RNA was extracted from both sides of the hippocampus in one single mouse (100 mg) using a Total RNA Isolation kit (cat. no. A27828; MagMAX MiRVana Total RNA Isolation kit; Thermo Fisher Scientific, Inc.). RNA (10 $\mu \mathrm{l})$, Oligo (dT)18 Primer $(0.5 \mu \mathrm{l})$ and Random Hexamer Primer $(0.5 \mu \mathrm{l})$ were mixed, then made up to $15 \mu 1$ using ribonuclease free deionized water. The mixture were reacted at $65^{\circ} \mathrm{C}$ for $5 \mathrm{~min}$ then cooled to room temperature. Subsequently, $4 \mu 15 \mathrm{X}$ Reaction Buffer and $1 \mu \mathrm{l}$ Servicebio RT Enzyme Mix (Wuhan Servicebio Technology Co., Ltd.) were added. The reaction conditions were: $42^{\circ} \mathrm{C} 60 \mathrm{~min}, 70^{\circ} \mathrm{C} 5 \mathrm{~min}$. qPCR was subsequently performed using SYBR Green qPCR Master Mix (MedChemExpress) and $2 \mu \mathrm{l}$ cDNA as a template. The reaction conditions were: $10 \mathrm{~min}$ at $95^{\circ} \mathrm{C}, 15 \mathrm{sec}$ at $95^{\circ} \mathrm{C}$ and $1 \mathrm{~min}$ at $60^{\circ} \mathrm{C}$. The RNA was amplified for a total of 40 cycles. The relative expression of miR-146a mRNA was calculated with U6 as the internal parameter using the $2^{-\Delta \Delta \mathrm{Cq}}$ method (24). RT-qPCR was performed in triplicate. The primer sequences were: miR-146a, F: 5'-CCTGAGAAGTGAATTCCATGGG-3' and R: 5'-CTCAACTGGTGTCGTGGAGTCGGCAATTCA GTTGAGAACCCATG-3'; U6, F: 5'-GGAGATTACTGCCCT GGCTCCTA-3' and R: 5'-GACTCATCGTACTCCTGCTTG CTG-3'.

ELISA. The concentrations of TNF- $\alpha$ (cat. no. BMS607-3FIVE) and IL-1 $\beta$ (cat. no. BMS6002) in the hippocampal tissue (100 mg) of mice or BV-2 cells (100 mg) were analyzed using an ELISA kit (Thermo Fisher Scientific, Inc.), according to the manufacturer's instructions.

Immunofluorescence. Following the behavioral tests, mice were anesthetized using $0.3 \%$ pentobarbital sodium $(45 \mathrm{mg} / \mathrm{kg}$ ) and sacrificed by decapitation. The hippocampus was dissected from the brain tissues and a portion was preserved at $-80^{\circ} \mathrm{C}$, while another portion was fixed in $4 \%$ paraformaldehyde at room temperature overnight, dehydrated and embedded in paraffin. Then the sections were cut into $4-\mu \mathrm{m}$ thick sections. The sections were dewaxed, treated with citrate buffer ( $\mathrm{pH}$ 6.0) antigen for $10 \mathrm{~min}$, inactivated with $3 \% \mathrm{H}_{2} \mathrm{O}_{2}$ for 20 min and sealed with 5\% BSA (cat. no. ml064298; Shanghai Enzyme-linked Biotechnology Co., Ltd.) for $20 \mathrm{~min}$. Rabbit anti-Iba-1 antibody (1:200; cat. no. ab48004, Abcam) was incubated and reacted overnight at $4^{\circ} \mathrm{C}$. Following rewarming, donkey polyclonal Secondary Antibody to Goat IgG-H\&L (Alexa Fluor ${ }^{\circledR} 488$; 1:200; cat. no. ab150129, Abcam) was incubated with secondary antibodies for $2 \mathrm{~h}$ at room temperature in dark. Following washing with PBS, DAPI (cat. no. I029-1-1, Nanjing Jiancheng Bioengineering Institute) was added and cultured for $3 \mathrm{~min}$ at room temperature. Following washing with PBS, anti-fluorescence quenching sealing agent (cat. no. IH0252; Beijing Leagene Biotech Co., Ltd.) was used to seal. A total of five fields were randomly selected at $\mathrm{x} 400$ magnification using a MiRax Scan (Zeiss GmbH, Jena) and the results were analyzed using ImageJ 1.49p (National Institutes of Health).

Western blotting. The expression levels of iNOS, IL-1 $\beta$, TRAF6, IRAK1 and NF- $\kappa$ B p65 in the hippocampus of each group or in BV-2 cells were detected by western blotting. Total protein in the tissue $(100 \mathrm{mg})$ or BV-2 cells was extracted using RIPA buffer containing protein inhibitors (cat. no. W062-1-1; Nanjing Jiancheng Bioengineering Institute) and the concentration of the protein sample was measured with a quantitative BCA Protein Assay kit (cat. no. 23225; Thermo Fisher Scientific, Inc.). Samples $(40 \mu \mathrm{g})$ from each group were collected, separated by $10 \%$ SDS-PAGE using a Mini-PROTEAN 3 (Bio-Rad Laboratories, Inc.) and transferred to a PVDF membrane (EMD Millipore). Blocking was performed using $5 \%$ skimmed milk for $1 \mathrm{~h}$ at $37^{\circ} \mathrm{C}$ and $5 \%$ BSA was used to dilute the following rabbit anti-mouse primary antibodies: iNOS (1:250; cat. no. ab15323; Abcam); IL-1 $\beta$ (1:2,000; cat. no. ab9722; Abcam); TNF- $\alpha$ (1:1,000, cat. no. ab183218; Abcam); TRAF6 (1:500; cat. no. ab62488; Abcam); IRAK1 (1:2,000; cat. no. ab238; Abcam); NF-кB p65 (1:1,000; cat. no. ab16502; Abcam); and $\beta$-actin (1:1,000; cat. no. ab8227; Abcam). Following incubation at $4{ }^{\circ} \mathrm{C}$ overnight, the membranes were washed 3 times with TBST (TBS, $1 \mathrm{ml} / 1$ Tween-20) for $10 \mathrm{~min}$ each time. Then they were incubated in goat anti-rabbit HRP IgG (1:2,000; cat. no. ab6721; Abcam) for $2 \mathrm{~h}$ at room temperature and the membrane was washed 3 times, for 10 min each time. Detection was performed using the enhanced chemiluminescence kit (cat. no. SW2010; Beijing Solarbio Science \& Technology Co., Ltd.). ImageJ software 1.49 p (National Institutes of Health) was used for grayscale image analysis.

Cell culture and treatment. The mouse microglial BV-2 cells were purchased from the Shanghai Institute of Biochemistry and Cell Biology. The cells were cultured in DMEM/F12 medium supplemented with $10 \%$ fetal bovine serum and $1 \%$ penicillin streptomycin (Gibco; Thermo Fisher Scientific, Inc.) in $5 \% \mathrm{CO}_{2}$ at $37^{\circ} \mathrm{C}$.

$\mathrm{BV}-2$ cells were randomly divided into 4 groups with 3 replicates: i) Control cells (Control); ii) LPS-treated (cells were stimulated with $1 \mu \mathrm{g} / \mathrm{ml}$ LPS) (16); iii) LPS + miR-146a mimic (miR-146a+LPS; cells were cultured with $1 \mu \mathrm{g} / \mathrm{ml}$ LPS for $24 \mathrm{~h}$, then transfected with $50 \mathrm{nM}$ miR-146a mimic); and iv) LPS + miR-146a negative control (miR-146a-NC+LPS). miR-146a mimic (5'-UGAGAACUGAAUUCCAUGGGUU-3') and negative control (Guangzhou RiboBio Co., Ltd.) were transfected using Lipofectamine ${ }^{\circledR} 3000$ reagent (Invitrogen; Thermo Fisher Scientific, Inc.) at $37^{\circ} \mathrm{C}$ and then added to the BV-2 cells. Following transfection for 48 h, miR-146a expression was assessed by RT-PCR.

Statistical analysis. Data analysis was performed using SPSS 19.0 software (IBM Corp.). All results are presented as the mean \pm standard deviation. Multiple data sets were compared using the one-way analysis of variance and Tukey's test was used for subsequent analyses. $\mathrm{P}<0.05$ was considered to indicate a statistically significant difference. 
A
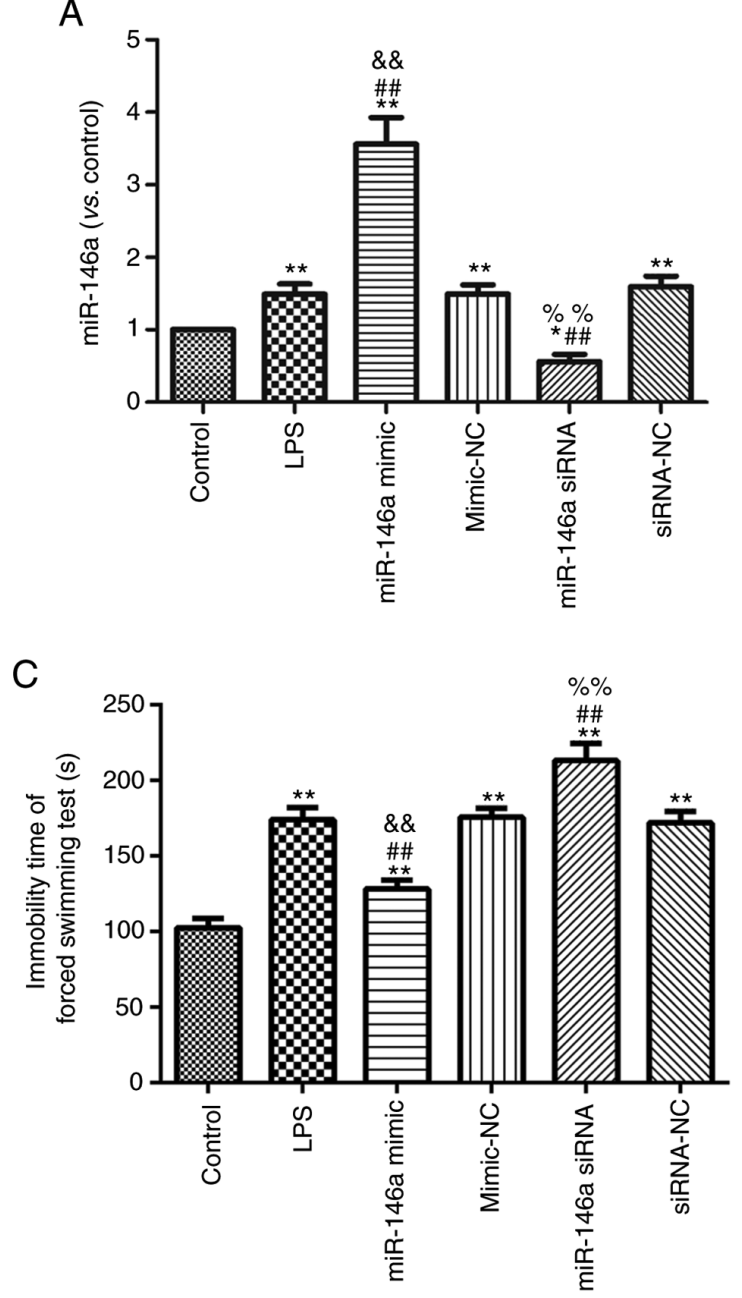

B

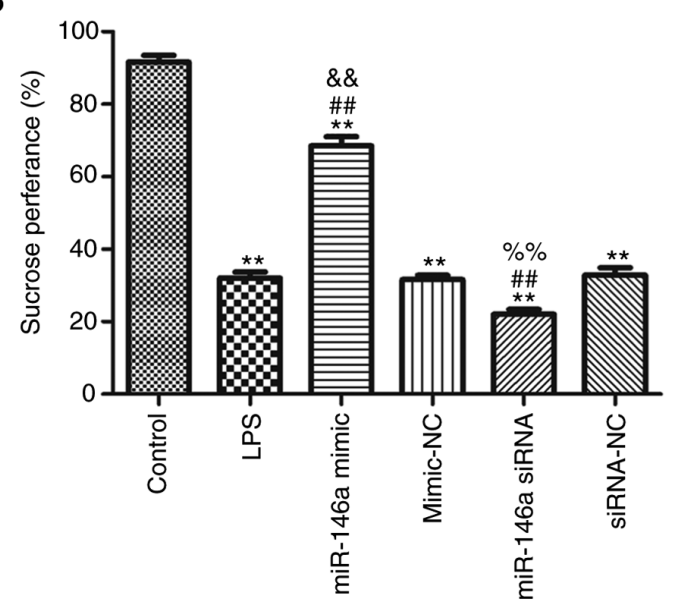

D

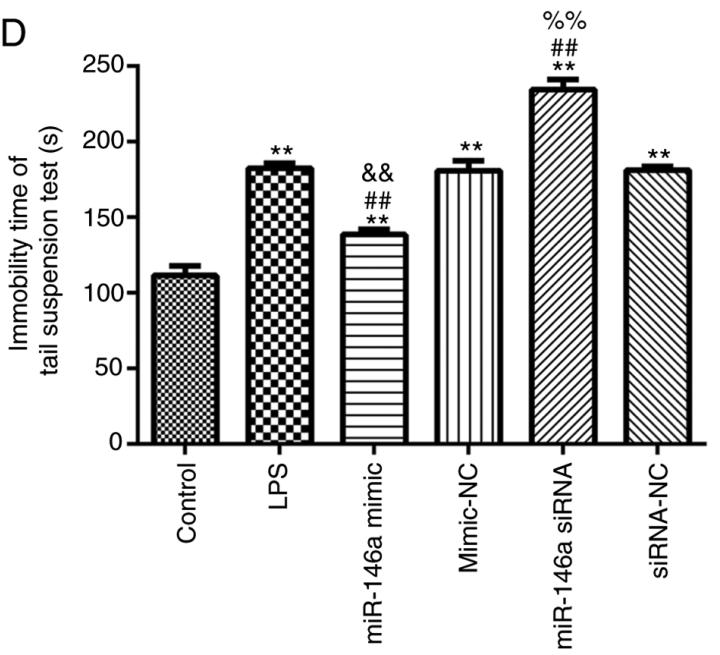

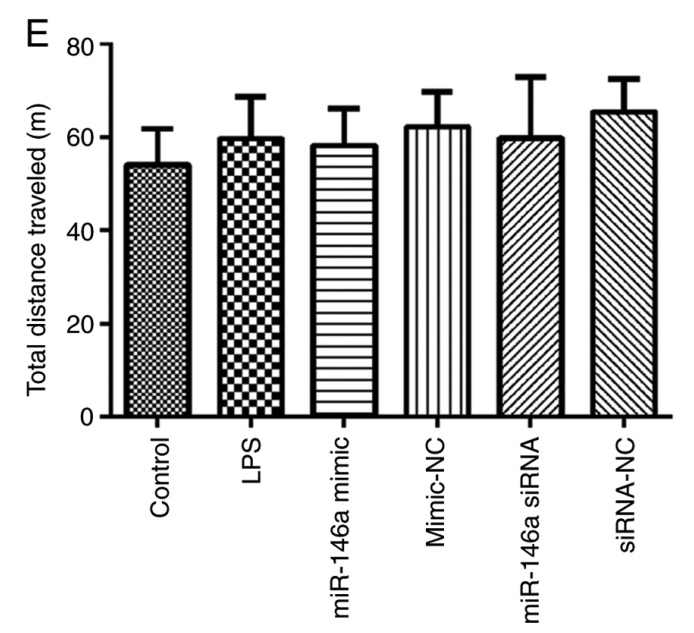

Figure 1. Overexpression of miR-146a reduced depression behaviors in LPS-induced mice. (A) miR-146a expression in every group. (B) Sucrose preference (C) Forced swimming test (D) Tail suspension test. (E) Locomotor activity. ${ }^{*} \mathrm{P}<0.05$ and ${ }^{* *} \mathrm{P}<0.01$ vs. control group; ${ }^{* \#} \mathrm{P}<0.01$ vs. LPS group; ${ }^{\text {\& }} \mathrm{P}<0.01$ vs. mimic-NC group; ${ }^{\%} \% \mathrm{P}<0.01$ vs. siRNA-NC group. miR, microRNA; LPS, lipopolysaccharide; NC, negative control; si, short interfering.

\section{Results}

Overexpression of miR-146a suppresses LPS-induced depression in mice. One week before LPS injection, miR-146a mimic and siRNA were injected into mice once every two days. After 1 week, mice were co-treated with LPS. Hippocampal miR-146a expression was measured in each experimental group using RT-PCR, as shown in Fig. 1A. Expression of miR-146a was significantly enhanced in the miR-146a mimic group, while miR-146a silencing effectively decreased miR-146a expression in the miR-146a siRNA group $(\mathrm{P}<0.05)$. The behavior of the mice in each group was tested and the results are shown in Fig. 1B-E. Compared with the control group, LPS induction significantly decreased sucrose preference (Fig. 1B) and significantly increased the scores on the FST (Fig. 1C) and the TST (Fig. 1D; all P<0.05). Overexpression of miR-146a 


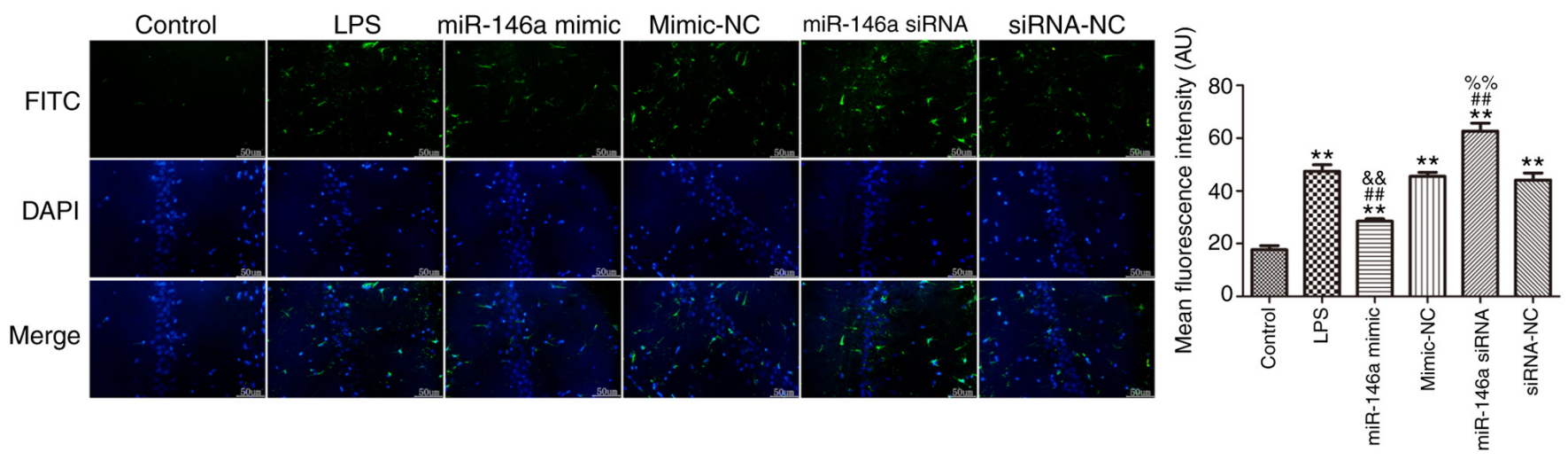

Figure 2. Overexpression of miR-146a suppressed the activation of microglia cells in the hippocampus of LPS induced mice. The expression level of Iba-1 in the hippocampus was measured by immunofluorescence. Magnification, $\mathrm{x} 400 .{ }^{* *} \mathrm{P}<0.01$ vs. control group; ${ }^{\# \#} \mathrm{P}<0.01$ vs. LPS group; ${ }^{\&} \mathrm{P}<0.01$ vs. mimic-NC group; ${ }^{\%} \%$ P $<0.01$ vs. siRNA-NC group. miR, microRNA; LPS, lipopolysaccharide; Iba-1, ionized calcium binding adapter molecule 1; NC, negative control; si, short interfering.

significantly enhanced sucrose preference and reduced the scores on the FST and the TST in the LPS-induced mice. miR-146a silencing significantly decreased sucrose preference and increased scores on the FST and the TST in LPS-induced mice (all $\mathrm{P}<0.05$ ). However, there was no significant difference in the total distance traveled among groups $(\mathrm{P}>0.05$; Fig. $1 \mathrm{E})$.

Overexpression of miR-146a suppresses microglial cell activation in the hippocampus of LPS-induced mice. Iba-1 was used as a specific marker of microglia cells and its expression was measured using immunofluorescence, as shown in Fig. 2. LPS induced a significant increase in Iba-1 expression in the hippocampus compared with the control group $(\mathrm{P}<0.01)$. Overexpression of miR-146a significantly attenuated the level of Iba-1 in the hippocampus of LPS-induced mice, while miR-146a silencing markedly increased the expression of Iba-1 $(\mathrm{P}<0.05)$.

Overexpression of miR-146a inhibits the expression of microglia-mediated neuroinflammatory proteins in the hippocampus of LPS-induced mice. Expression levels of microglia-mediated neuroinflammatory proteins were measured in the hippocampus of the experimental mice (Fig. 3). Compared with the control group, the expression levels of iNOS, IL-1 $\beta$, TNF- $\alpha$, IRAK1, TRAF6 and p-NF- $\kappa$ B p65 in the LPS-induced group were significantly increased $(\mathrm{P}<0.05)$. Overexpression of miR-146a effectively inhibited the expression levels of these neuroinflammatory proteins, while miR-146a silencing significantly upregulated their expression compared with LPS group $(\mathrm{P}<0.01)$.

Overexpression of miR-146a reduces depressive behaviors in CUMS mice. In order to study the effect of miR-146a on depressed mice, miR-146a mimic and siRNA were used to treat CUMS mice (Fig. 4A). Compared with the untreated CUMS group, miR-146a expression in the hippocampal region of CUMS mice was effectively increased following treatment with miR-146a agomir, but significantly decreased following treatment with miR-146a antagomir (both $\mathrm{P}<0.05$ ). The behaviors of CUMS mice were also tested (Fig. 4B-D). In contrast to the Control group, sucrose preference (Fig. 4B) was notably decreased in the CUMS group, but scores on the FST (Fig. 4C) and the TST (Fig. 4D) were significantly increased (all $\mathrm{P}<0.05$ ). Following overexpression of miR-146a, sucrose preference was clearly increased in the CUMS mice and scores on the FST and the TST were significantly decreased (all $\mathrm{P}<0.05)$. Meanwhile, miR-146a silencing led to more serious behavioral impairments compared with those in the CUMS group $(\mathrm{P}<0.05)$. There was no difference in locomotor activity among groups ( $\mathrm{P}>0.05$; Fig. $1 \mathrm{E})$.

Overexpression of miR-146a suppresses activation of microglia in the hippocampus of CUMS mice. The expression level of Iba-1 in the hippocampus of CUMS mice was measured by immunofluorescence, as shown in Fig. 5. Iba-1 expression was effectively increased in CUMS mice compared with that in control mice $(\mathrm{P}<0.05)$. Overexpression of miR-146a significantly suppressed Iba-1 expression in the hippocampus of CUMS mice, while miR-146a silencing significantly promoted Iba-1 expression (both $\mathrm{P}<0.05$ ). This indicates that microglia in the hippocampus of CUMS mice become abnormally activated and that overexpression of miR-146a can significantly reduce such activation.

Overexpression of miR-146a suppresses microglia-mediated neuroinflammatory proteins in the hippocampus of CUMS mice. The expression levels of iNOS, IL- $1 \beta$, TNF- $\alpha$, IRAK1, TRAF6 and p-NF- $\kappa$ B p65 in the hippocampus in CUMS mice were significantly enhanced compared with those in control mice $(\mathrm{P}<0.05$; Fig. 6). Overexpression of miR-146a effectively lowered the expression levels of these proteins, while miR-146a silencing effectively increased their expression $(\mathrm{P}<0.05$; Fig. 6). These data suggest that overexpression of miR-146a markedly inhibits microglia-mediated neuroinflammatory protein expression.

Overexpression of miR-146a suppresses the neuroinflammatory response in LPS-induced BV-2 cells. The expression of miR-146a was quantified, as shown in Fig. 7A. Following transfection with miR-146a mimic, the level of miR-146a was clearly increased compared with that of the LPS group $(\mathrm{P}<0.05)$. Additionally, transfection with miR-146a 
A
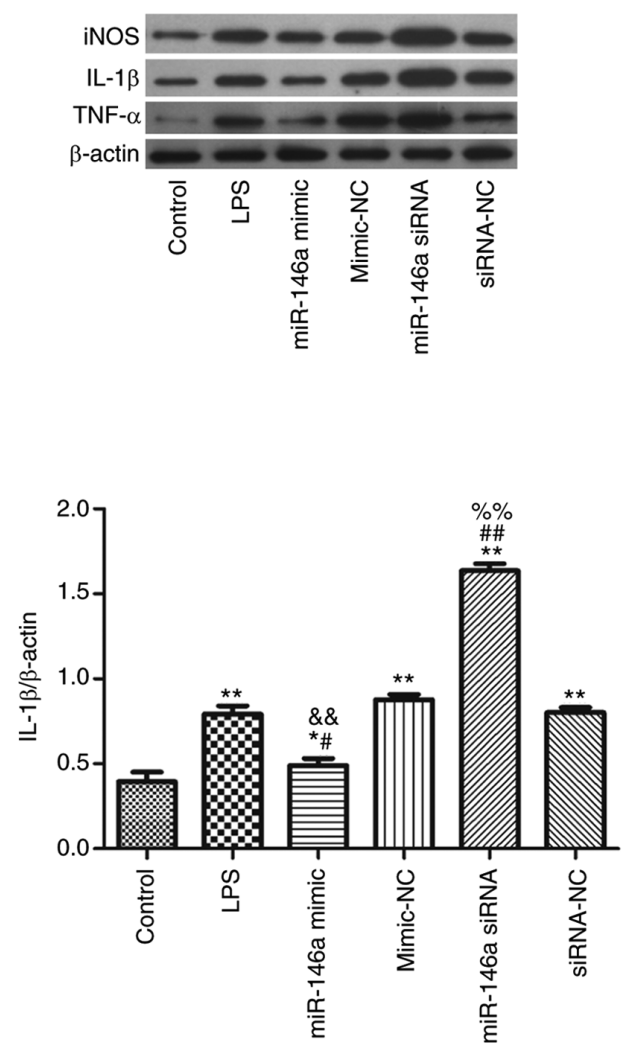

B
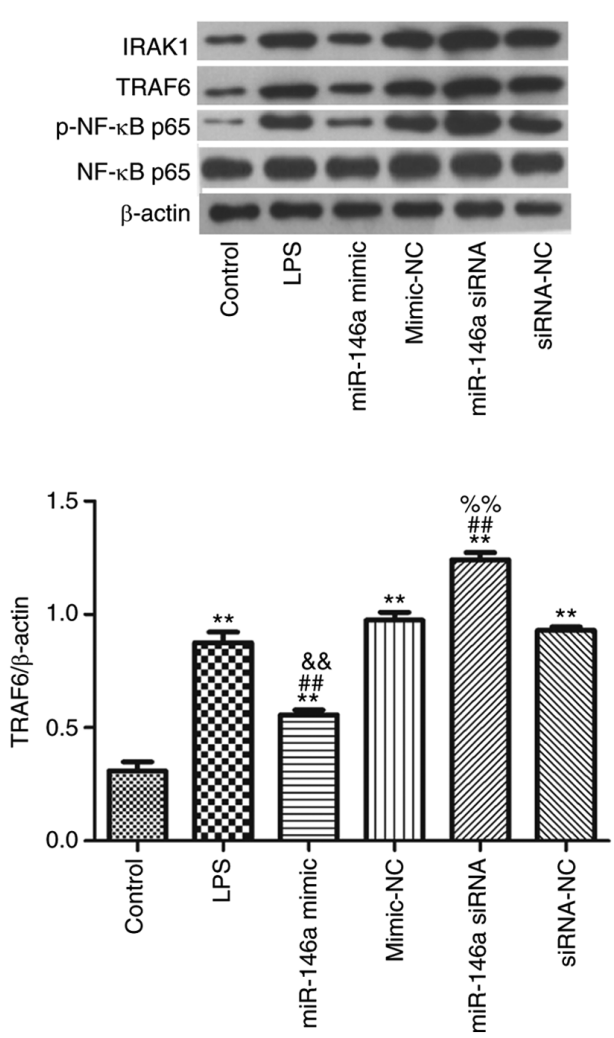
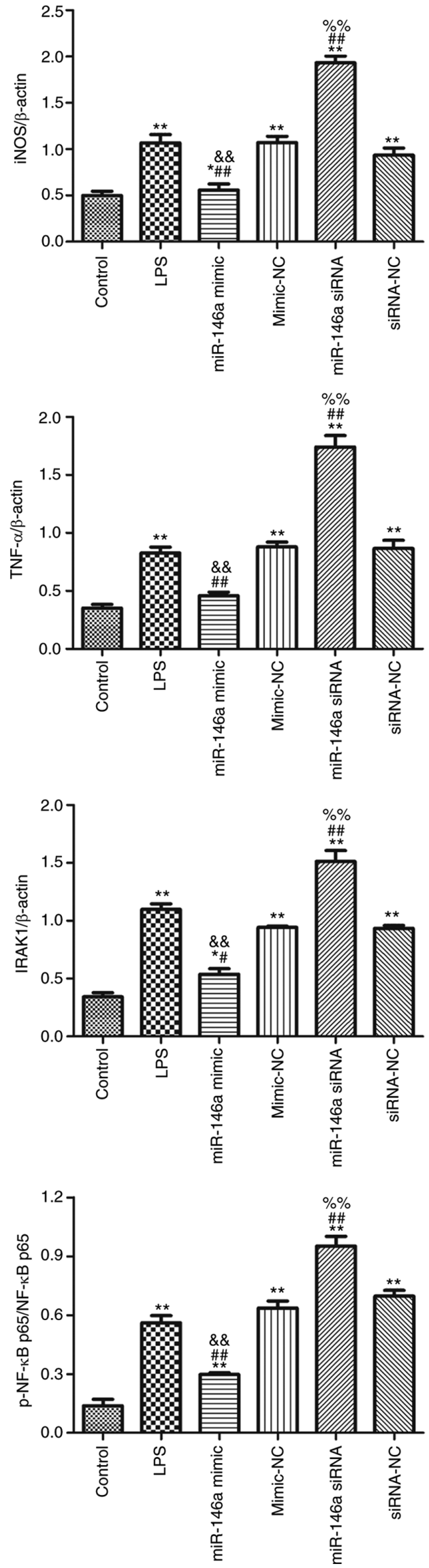

Figure 3. Overexpression of miR-146a inhibited neuroinflammatory response in hippocampus of LPS-induced mice. (A) The relative expression of iNOS, IL-1 $\beta$, TNF- $\alpha$; (B) The relative expression of IRAK1, TRAF6, p-NF- $\kappa B$ p65/ NF- $\kappa B$ p65. " $\mathrm{P}<0.05$ and ${ }^{* *} \mathrm{P}<0.01$ vs. control group; ${ }^{\#} \mathrm{P}<0.05$ and ${ }^{\# \prime} \mathrm{P}<0.01$ vs. LPS group; ${ }^{\&} \mathrm{P}<0.01$ vs. mimic-NC group; ${ }^{\%} \% \mathrm{P}<0.01$ vs. siRNA-NC group. miR, microRNA; LPS, lipopolysaccharide; NC, negative control; si, short interfering; iNOS, inducible nitric oxide synthase; IRAK1, recombinant interleukin 1 receptor-associated kinase 1; TRAF6, TNF receptor-associated factor 6; p-, phosphorylated. 
A

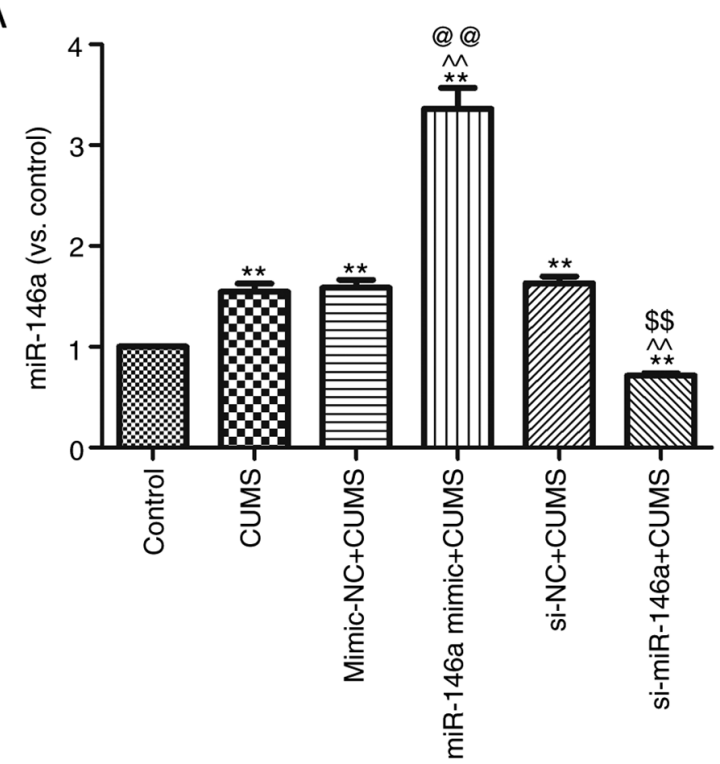

C

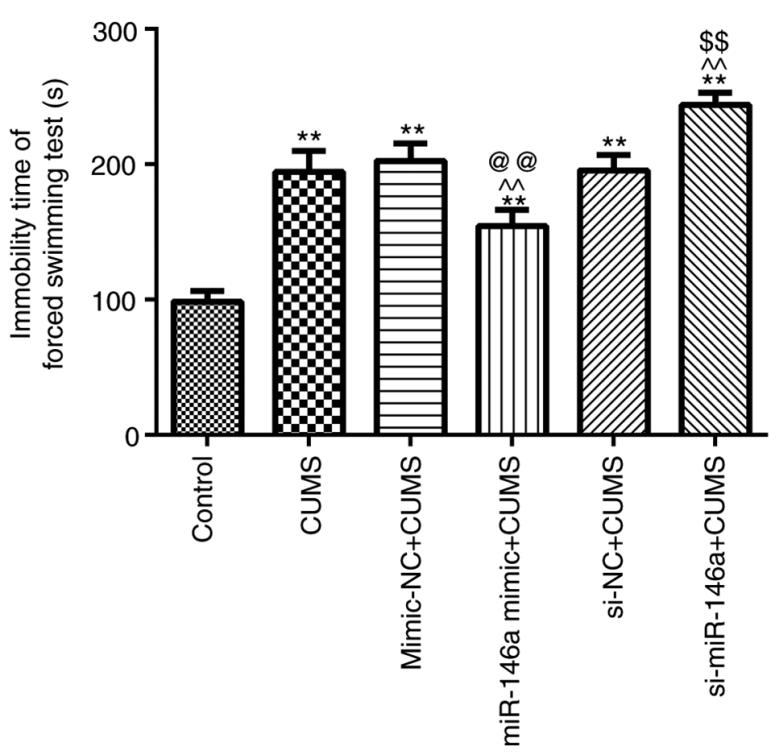

B

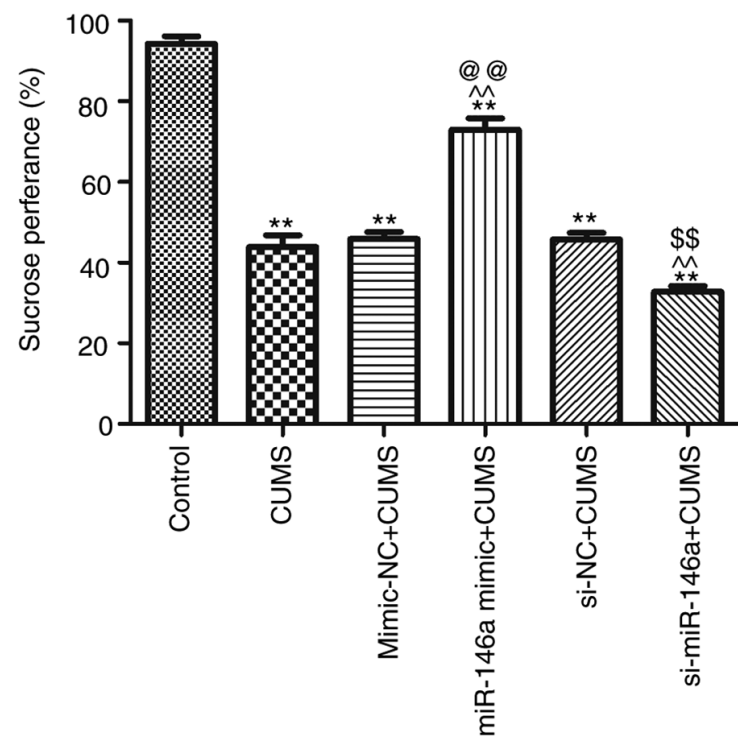

D
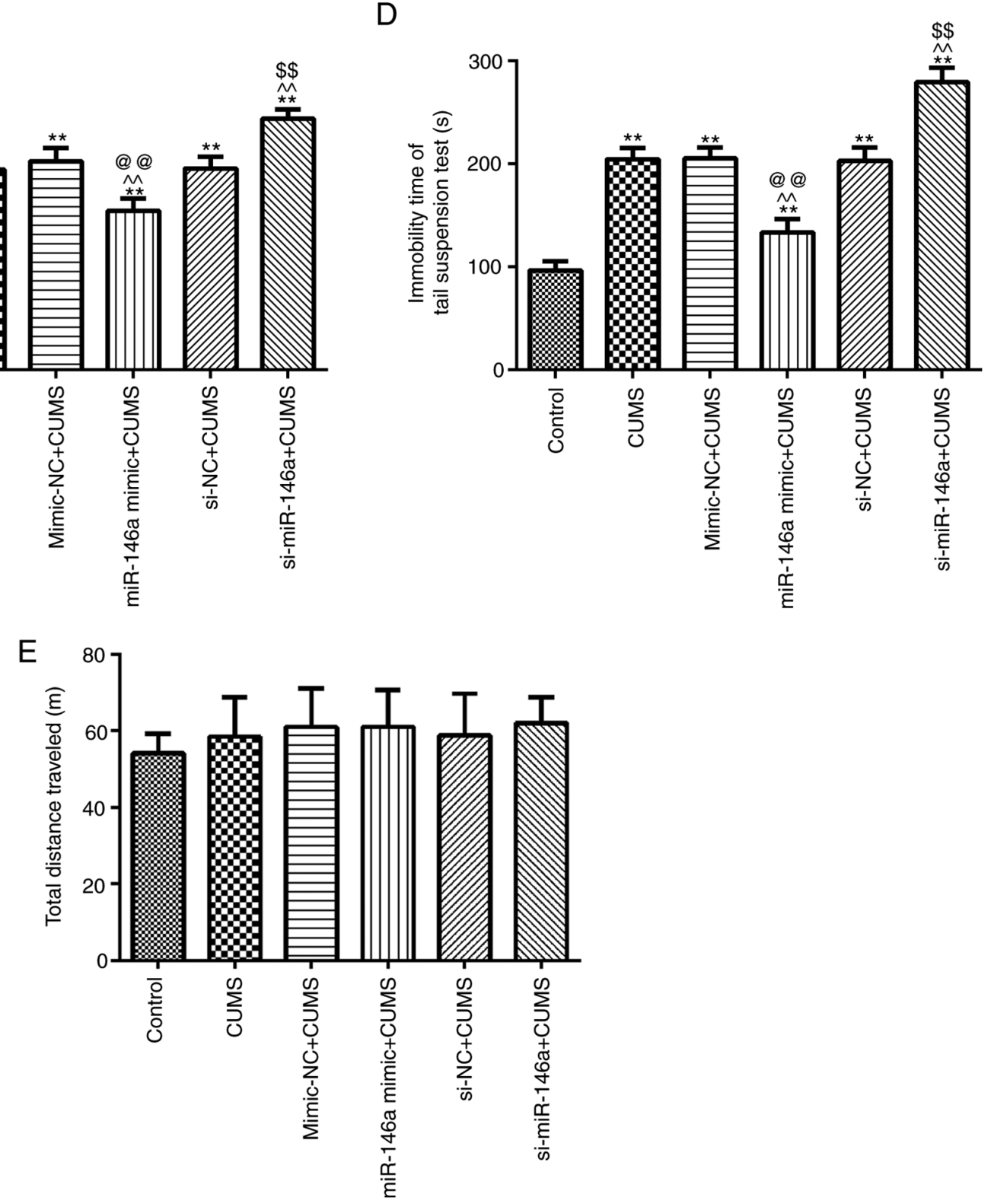

Figure 4. Overexpression of miR-146a repressed depression behaviors in CUMS mice. (A) miR-146a expression of mice. (B) Sucrose preference. (C) Forced swimming test. (D) Tail suspension test. (E) Locomotor activity. ${ }^{* *} \mathrm{P}<0.01$ vs. control group; ${ }^{\wedge} \mathrm{P}<0.01$ vs. CUMS group; ${ }^{\circledR}{ }^{\circledR} \mathrm{P}<0.01 \mathrm{vs}$. mimic-NC $+\mathrm{CUMS}$ group; ${ }^{\$ \$} \mathrm{P}<0.01$ vs. siRNA-NC + CUMS group. miR, microRNA; CUMS, chronic unpredictable mild stress; NC, negative control; si, short interfering. 


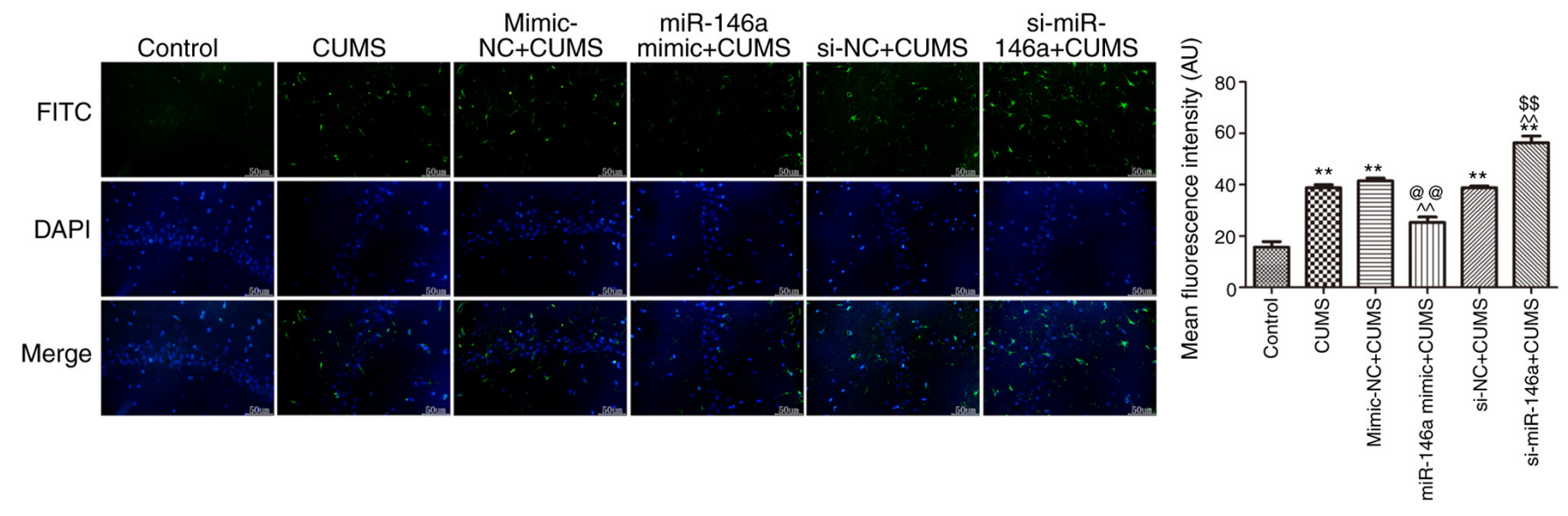

Figure 5. The expression level of Iba-1 in the hippocampus of CUMS mice was measured by immunofluorescence (magnification, $\mathrm{x} 400$ ). ${ }^{* *} \mathrm{P}<0.01 \mathrm{vs.}$ control group; ${ }^{\wedge} \mathrm{P}<0.01$ vs. CUMS group; ${ }^{@}{ }^{@} \mathrm{P}<0.01$ vs. mimic-NC + CUMS group; ${ }^{\$ \$} \mathrm{P}<0.01$ vs. siRNA-NC + CUMS group. Iba-1, ionized calcium binding adapter molecule 1; CUMS, chronic unpredictable mild stress; NC, negative control; si, short interfering; miR, microRNA; AU, arbitrary units.

mimic notably decreased the levels of IL-1 $\beta$ and TNF- $\alpha$ in LPS-induced BV-2 cells compared with those of LPS-treated cells (Fig. 7B; $\mathrm{P}<0.05$ ). The western blotting results showed that levels of IL-1 $\beta$, TNF- $\alpha$, IRAK1 and TRAF6 were significantly reduced in the miR-146a+LPS group compared with those in the miR-146a-NC+LPS group (Fig. 7C; $\mathrm{P}<0.05$ ).

\section{Discussion}

In the present study, two mouse models of depression were established, namely the LPS-induced depression and CUMS depression models. Notably, miR-146a was expressed at a high level in depressed mice accompanied with increased expression of IRAK1 and TRAF6. Further investigation showed that overexpression of miR-146a suppressed microglial activation in the hippocampus of depressed mice and inhibited neuroinflammation-related proteins, including iNOS, IL-1 $\beta$, IRAK1, TRAF6 and p-NF- $\mathrm{B}$ p65. From these contradictory results, it may be that the expression of miR-146a was too low to suppress the expression of inflammatory proteins in depression models. However, the mechanisms of miR-146a for neuroinflammation require further elucidation.

The LPS immune activation model is an important animal model for studying the cytokine hypothesis of depression. A number of studies have shown that depression is associated with immune activation and manifests as an increased expression of pro-inflammatory cytokines (25-27). Immune activation results in changes of mood and behavior; therefore, cytokines can be seen as biomarkers for depression. Cytokines are divided into pro-inflammatory cytokines and anti-inflammatory cytokines (28). The present study found that the pro-inflammatory factors iNOS, TNF- $\alpha$ and IL- $1 \beta$ were clearly increased in hippocampus of depressed mice. In a study of surgical trauma-induced cognitive decline in mice, miR-146a suppresses hippocampal neuroinflammation and improve cognitive function (16). In an Alzheimer's disease mouse model, intranasal administration of miR-146a agomir rescues the pathological process and cognitive impairment (29). Consistent with these previous studies $(16,29)$, the present study found that injection of miR-146a mimic suppressed TNF- $\alpha$ and IL-1 $\beta$ expression and also ameliorated depression-like behaviors, as measured by the SPT, FST and TST. The data suggested that miR-146a served a positive role in depression. The theoretical basis of the CUMS model is close to that of human depression; that is, depression is promoted by medium-chronic and low-level stressors (30). Consistent with LPS-induced depression, expression levels of iNOS and IL-1 $\beta$ were clearly increased, while miR-146a inhibited pro-inflammatory factor expression.

Recent studies have shown that microglial activation is closely related to depression (3-5). Postmortem examination of the dorsal anterior cingulate cortex in patients with major depression has revealed microglial activation and macrophage aggregation (31). The immune response of the central nervous system is mainly regulated by microglia and astrocytes. Similarly, the present study found that microglial cells were activated in the hippocampus of depressed mice. Together, these studies suggest that microglial activation can be considered an important marker of depression. Therefore, exploring how to inhibit the activation of microglia is essential to treating patients with depression. miR-146a has been shown to serve a protective role in surgical trauma-induced cognitive decline in mice via suppression of the IRAK1/TRAF6/NF- $\kappa \mathrm{B}$ pathway in the hippocampus (16). Based on these previous reports, it was hypothesized that miR-146a acted as a positive regulator for depression, suppressing microglial activation and neuroinflammation in the hippocampus.

The results of the present study supported the hypothesis that miR-146a effectively inhibited the activation of microglial cells and suppressed levels of IRAK1, TRAF6 and NF- $\kappa$ B p65 in the hippocampus of depressed mice. The present study suggested, for the first time to the best of the authors' knowledge, that miR-146a acted as an antidepressant by inhibiting microglial activation. However, more experimental studies are needed to explore the role that microRNAs serve in the pathogenesis of depression.

In summary, the present study found that miR-146a overexpression inhibited microglial activation by reducing levels of the neuroinflammation-related proteins TRAF6, IRAK1 and $\mathrm{NF}-\kappa \mathrm{B}$ p65 in the hippocampus of depressed mice. 

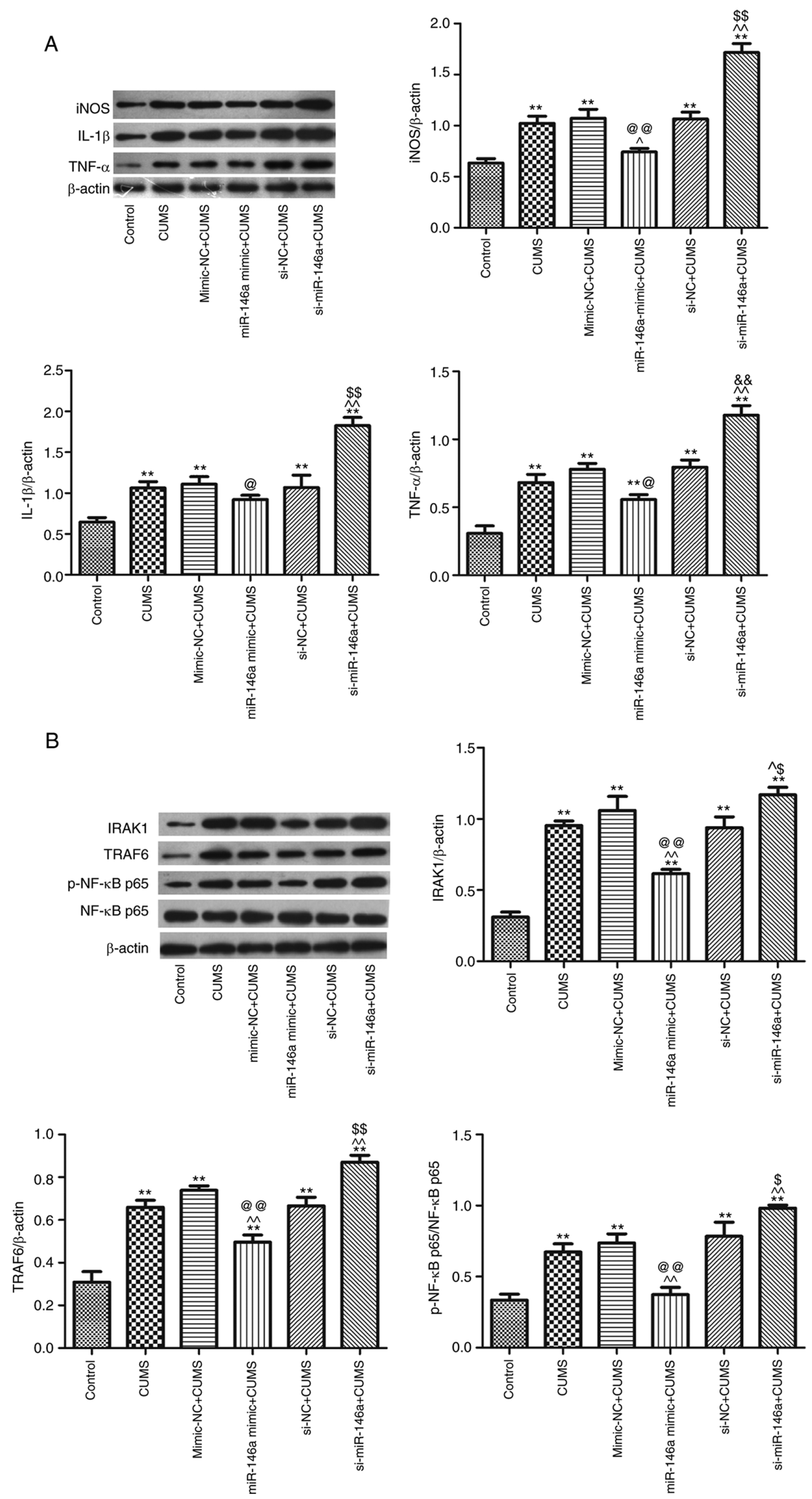

Figure 6. Overexpression of miR-146a inhibits neuroinflammatory response in hippocampus of CUMS mice. (A) The relative expression of iNOS, IL-1 $\beta$,

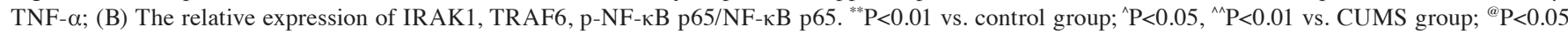
and ${ }^{@ @} \mathrm{P}<0.01$ vs. mimic-NC + CUMS group; ${ }^{\$} \mathrm{P}<0.05$ and ${ }^{\$} \mathrm{P}<0.01$ vs. siRNA-NC + CUMS group. miR, microRNA; CUMS, chronic unpredictable mild stress; iNOS, inducible nitric oxide synthase; IRAK1, recombinant interleukin 1 receptor-associated kinase 1; TRAF6, TNF receptor-associated factor 6; p-, phosphorylated; NC, negative control; si, short interfering. 
A

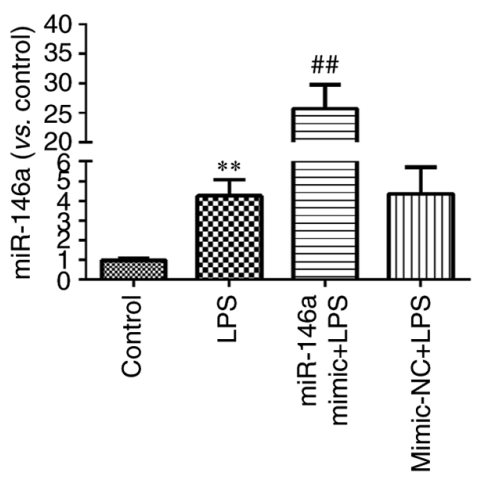

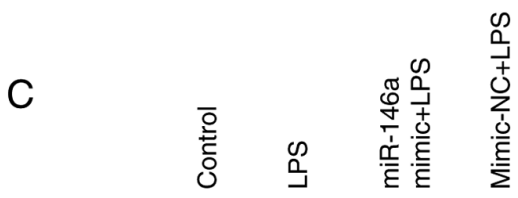

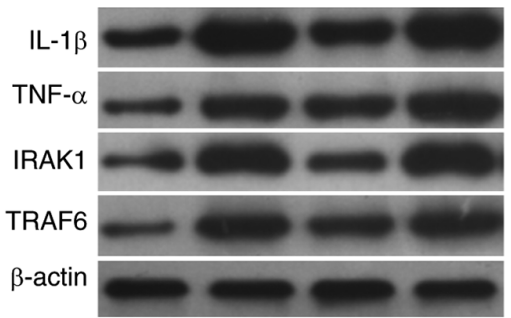

B

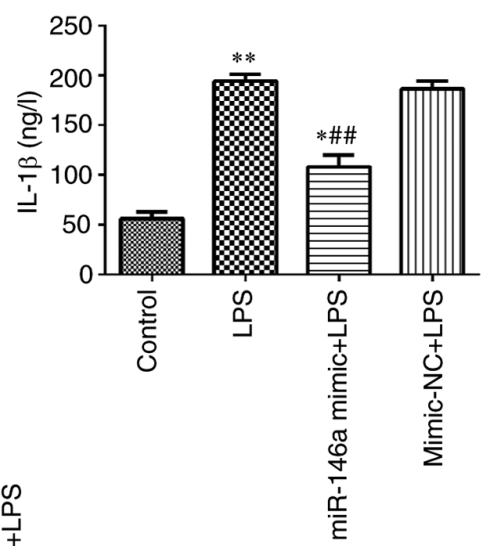

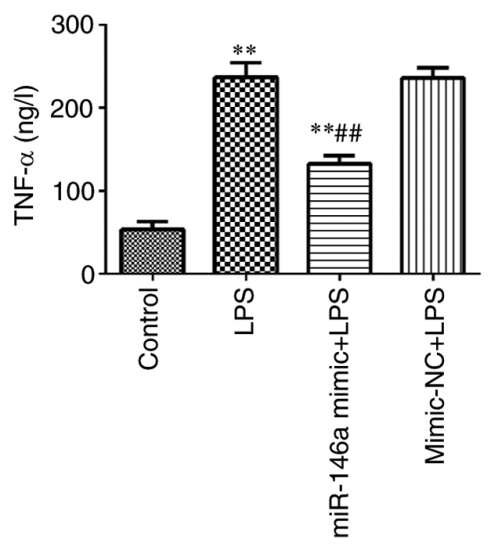
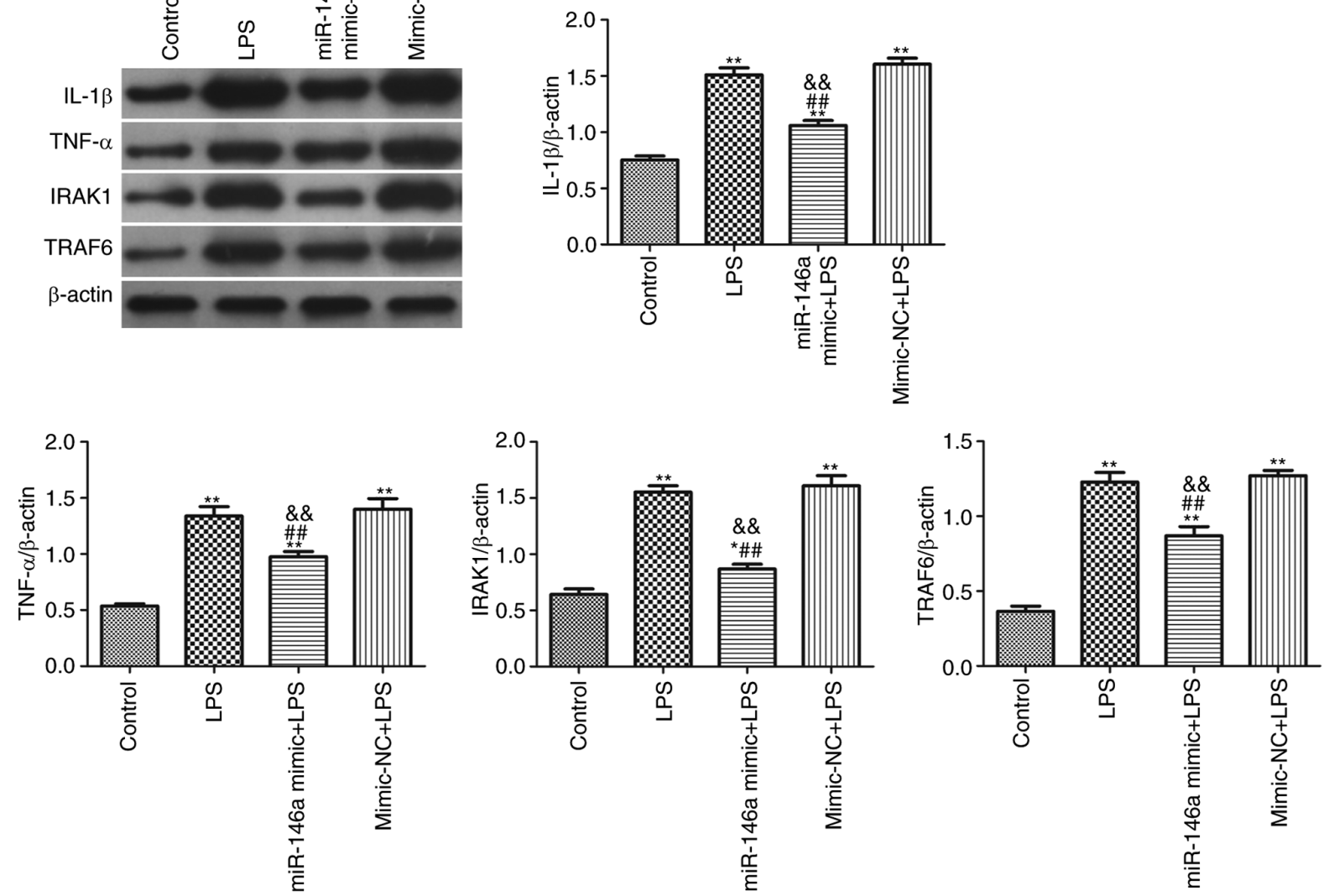

Figure 7. Overexpression of miR-146a inhibits neuroinflammatory response in LPS induced BV-2 cells. (A) miR-146a expression in every group; (B) The expression of TNF- $\alpha$ and IL-1 $\beta$ were analyzed by ELISA. (C) The relative expression of IL-1 $\beta$, TNF- $\alpha$, IRAK1 and TRAF6 were analyzed by western blotting. ${ }^{*} \mathrm{P}<0.05$ and ${ }^{* *} \mathrm{P}<0.01$ vs. control group; ${ }^{\# \#} \mathrm{P}<0.01$ vs. LPS group; ${ }^{\&}{ }^{\&} \mathrm{P}<0.01$ vs. mimic-NC group. miR, microRNA; LPS, lipopolysaccharide; IRAK1, recombinant interleukin 1 receptor-associated kinase 1; TRAF6, TNF receptor-associated factor 6; NC, negative control; si, short interfering; NC, negative control.

\section{Acknowledgements}

Not applicable.

\section{Funding}

No funding was received.

\section{Availability of data and materials}

The analyzed data sets generated during the study are available from the corresponding author on reasonable request.

\section{Authors' contributions}

CPL and MZ carried out the experimental work and the data collection and interpretation. CPL, MZ and JXS participated in the design and coordination of experimental work and acquisition of data. JH, FXQ and YG participated in the data collection, analysis of data and preparation of the manuscript. CPL, MZ and JXS carried out the study design, the analysis and interpretation of data and drafted the manuscript. CPL and MZ confirm the authenticity of all the raw data. All authors have read and approved the final manuscript. 


\section{Ethics approval and consent to participate}

The study has been approved by the Institutional Animal Care and Use Committee (IACUC) of Binzhou People's Hospital (201910072).

\section{Patient consent for publication}

Not applicable.

\section{Competing interests}

The authors declare that they have no competing interests.

\section{References}

1. Carlessi AS, Borba LA, Zugno AI, Quevedo J and Reus GZ: Gut-microbiota-brain axis in depression: The role of neuroinflammation. Eur J Neurosci 53: 222-235, 2021

2. Amidfar M, Reus GZ, Quevedo J and Kim YK: The role of memantine in the treatment of major depressive disorder: Clinical efficacy and mechanisms of action. Eur J Pharmacol 827: 103-111, 2018.

3. Shibata M and Suzuki N: Exploring the role of microglia in cortical spreading depression in neurological disease. J Cereb Blood Flow Metab 37: 1182-1191, 2017.

4. Yirmiya R, Rimmerman N and Reshef R: Depression as a microglial disease. Trends Neurosci 38: 637-658, 2015.

5. Zhou S, Chen S, Xie W, Guo X and Zhao J: Microglia polarization of hippocampus is involved in the mechanism of Apelin-13 ameliorating chronic water immersion restraint stress-induced depression-like behavior in rats. Neuropeptides 81: 102006, 2020.

6. Mikita J, Dubourdieu-Cassagno N, Deloire MS, Vekris A, Biran M, Raffard G, Brochet B, Canron MH, Franconi JM, Boiziau C and Petry KG: Altered M1/M2 activation patterns of monocytes in severe relapsing experimental rat model of multiple sclerosis. Amelioration of clinical status by M2 activated monocyte administration. Mult Scler 17: 2-15, 2011.

7. Tobon-Velasco JC, Cuevas E and Torres-Ramos MA: Receptor for AGEs (RAGE) as mediator of $\mathrm{NF}-\kappa \mathrm{B}$ pathway activation in neuroinflammation and oxidative stress. CNS Neurol Disord Drug Targets 13: 1615-1626, 2014.

8. Hui B, Zhang L, Zhou Q and Hui L: Pristimerin inhibits LPS-triggered neurotoxicity in BV-2 Microglia cells through modulating IRAK1/TRAF6/TAK1-Mediated NF- $\mathrm{B}$ and AP-1 signaling pathways in vitro. Neurotox Res 33: 268-283, 2018.

9. Testa U, Pelosi E, Castelli G and Labbaye C: miR-146 and miR-155: Two key modulators of immune response and tumor development. Noncoding RNA 3: 22, 2017

10. Taganov KD, Boldin MP, Chang KJ and Baltimore D: NF-kappaB-dependent induction of microRNA miR-146, an inhibitor targeted to signaling proteins of innate immune responses. Proc Natl Acad Sci USA 103: 12481-12486, 2006.

11. He X, Zheng Y, Liu S, Shi S, Liu Y, He Y, Zhang C and Zhou X: MiR-146a protects small intestine against ischemia/reperfusion injury by down-regulating TLR4/TRAF6/NF- $\mathrm{BB}$ pathway. J Cell Physiol 233: 2476-2488, 2018.

12. Loubaki L, Chabot D, Pare I, Drouin M and Bazin R: MiR-146a potentially promotes IVIg-mediated inhibition of TLR4 signaling in LPS-activated human monocytes. Immunol Lett 185: 64-73, 2017.

13. Deng M, Du G, Zhao J and Du X: miR-146a negatively regulates the induction of proinflammatory cytokines in response to Japanese encephalitis virus infection in microglial cells. Arch Virol 162: 1495-1505, 2017.

14. Sharma N, Verma R, Kumawat KL, Basu A and Singh SK: miR-146a suppresses cellular immune response during Japanese encephalitis virus JaOArS982 strain infection in human microglial cells. J Neuroinflammation 12: 30, 2015.
15. Ren Z, Yan P, Zhu L, Yang H, Zhao Y, Kirby BP, Waddington JL and Zhen X: Dihydromyricetin exerts a rapid antidepressant-like effect in association with enhancement of BDNF expression and inhibition of neuroinflammation. Psychopharmacology (Berl) 235: 233-244, 2018.

16. Chen L, Dong R, Lu Y, Zhou Y, Li K, Zhang Z and Peng M: MicroRNA-146a protects against cognitive decline induced by surgical trauma by suppressing hippocampal neuroinflammation in mice. Brain Behav Immun 78: 188-201, 2019.

17. Singhal G and Baune BT: Microglia: An interface between the loss of neuroplasticity and depression. Front Cell Neurosci 11: $270,2017$.

18. Ma K, Guo L, Xu A, Cui S and Wang JH: Molecular mechanism for stress-induced depression assessed by sequencing miRNA and mRNA in medial prefrontal cortex. PLoS One 11: e0159093, 2016.

19. Ma K, Xu A, Cui S, Sun MR, Xue YC and Wang JH: Impaired GABA synthesis, uptake and release are associated with depression-like behaviors induced by chronic mild stress. Transl Psychiatry 6: e910, 2016.

20. Strekalova T, Couch Y, Kholod N, Boyks M, Malin D, Leprince P and Steinbusch HM: Update in the methodology of the chronic stress paradigm: Internal control matters. Behav Brain Funct 7: 9, 2011.

21. Rupniak NM,Carlson EJ, Webb JK, Harrison T,PorsoltRD, Roux S, de Felipe C, Hunt SP, Oates B and Wheeldon A: Comparison of the phenotype of NK1R-/- mice with pharmacological blockade of the substance $\mathrm{P}$ (NK1) receptor in assays for antidepressant and anxiolytic drugs. Behav Pharmacol 12: 497-508, 2001.

22. Zomkowski AD, Santos AR and Rodrigues AL: Putrescine produces antidepressant-like effects in the forced swimming test and in the tail suspension test in mice. Prog Neuropsychopharmacol Biol Psychiatry 30: 1419-1425, 2006.

23. Nishida S, Araki R, Baba A, Asari S, Tachibana S, Nakajima Y, Iwakumo A and Yabe T: Post-weaning folate deficiency induces a depression-like state via neuronal immaturity of the dentate gyrus in mice. J Pharmacol Sci 143: 97-105, 2020.

24. Livak JK and Schmittgen TD: Analysis of relative gene expression data using quantitative PCR and the 2(-Delta Delta C(T)) method. Methods 25: 402-408, 2001.

25. Leff-Gelman P, Mancilla-Herrera I, Flores-Ramos M, Cruz-Fuentes C, Reyes-Grajeda JP, García-Cuétara Mdel P, Bugnot-Pérez MD and Pulido-Ascencio DE: The immune system and the role of inflammation in perinatal depression. Neurosci Bull 32: 398-420, 2016

26. Robson MJ, Quinlan MA and Blakely RD: Immune system activation and depression: Roles of serotonin in the central nervous system and periphery. ACS Chem Neurosci 8: 932-942, 2017.

27. Ronovsky M, Berger S, Zambon A, Reisinger SN, Horvath O, Pollak A, Lindtner C, Berger A and Pollak DD: Maternal immune activation transgenerationally modulates maternal care and of fspring depression-like behavior. Brain Behav Immun 63: 127-136, 2017.

28. Kim YK, Na KS, Myint AM and Leonard BE: The role of pro-inflammatory cytokines in neuroinflammation, neurogenesis and the neuroendocrine system in major depression. Prog Neuropsychopharmacol Biol Psychiatry 64: 277-284, 2016.

29. Mai H, Fan W, Wang Y, Cai Y, Li X, Chen F, Chen X, Yang J, Tang $\mathrm{P}$, Chen $\mathrm{H}$, et al: Intranasal administration of miR-146a agomir rescued the pathological process and cognitive impairment in an AD mouse model. Mol Ther Nucleic Acids 18: 681-695, 2019.

30. Li H, Linjuan L and Wang Y: G-CSF improves CUMS-induced depressive behaviors through downregulating Ras/ERK/MAPK signaling pathway. Biochem Biophys Res Commun 479: 827-832, 2016.

31. Bollinger JL and Wohleb ES: The formative role of microglia in stress-induced synaptic deficits and associated behavioral consequences. Neurosci Lett 711: 134369, 2019.

This work is licensed under a Creative Commons Attribution-NonCommercial-NoDerivatives 4.0 International (CC BY-NC-ND 4.0) License. 